\title{
Article \\ Soft Bio-Integrated Multifunctional Devices Using an Intrinsically Stretchable Conducting Nanomembrane
}

\author{
Sangkyu Lee ${ }^{1,+}\left(\mathbb{D}\right.$, Kyumin Kang ${ }^{1,+} \oplus$, Heewon Choi ${ }^{1}$, Jiyong Yoon ${ }^{1}$, Yewon Kim ${ }^{1}$, Soojung An ${ }^{1}$, Hyunjin Jung ${ }^{2}$, \\ Duhwan Seong ${ }^{1}$, Kyuha Park ${ }^{1}$, Hyoungwon Baac ${ }^{1}$ (D) and Donghee Son ${ }^{1,3, * \mathbb{C}}$
}

1 Department of Electrical and Computer Engineering, Sungkyunkwan University (SKKU), Suwon 16419, Korea; lee39@g.skku.edu (S.L.); zseqqq@gmail.com (K.K.); chwchw97@gmail.com (H.C.); jiyong428@g.skku.edu (J.Y.); ywkim0726@gmail.com (Y.K.); soojung2134@gmail.com (S.A.); dodoworld1993@gmail.com (D.S.); telos6063@gmail.com (K.P.); hwbaac@skku.edu (H.B.)

2 School of Mechanical Engineering, Sungkyunkwan University (SKKU), Suwon 16419, Korea; hyunjin.jung33@gmail.com

3 Department of Superintelligence Engineering, Sungkyunkwan University (SKKU), Suwon 16419, Korea

* Correspondence: daniel3600@g.skku.edu; Tel./Fax: +82-312907696

+ These authors contributed equally to this work.

check for

updates

Citation: Lee, S.; Kang, K.; Choi, H.; Yoon, J.; Kim, Y.; An, S.; Jung, H.; Seong, D.; Park, K.; Baac, H.; et al. Soft Bio-Integrated Multifunctional Devices Using an Intrinsically Stretchable Conducting Nanomembrane. Appl. Sci. 2021, 11, 6562. https://doi.org/10.3390/ app11146562

Academic Editor: Giuseppe Andreoni

Received: 16 June 2021

Accepted: 15 July 2021

Published: 16 July 2021

Publisher's Note: MDPI stays neutral with regard to jurisdictional claims in published maps and institutional affiliations.

Copyright: (c) 2021 by the authors. Licensee MDPI, Basel, Switzerland. This article is an open access article distributed under the terms and conditions of the Creative Commons Attribution (CC BY) license (https:// creativecommons.org/licenses/by/ $4.0 /)$.

\begin{abstract}
Soft bioelectronic systems with a unique mechanical property, namely modulus matching between human skin (or tissue) and the device, have gained widespread attention. This is because of their closed-loop strain-insensitive electrical performance ranging from application in the longterm stable measurements of physiological signals and feedback modulation to human skin (or organs). Various materials and integration/fabrication strategies such as buckled, rigid islands, and wavy designs addressed for soft bioelectronic systems require complex device fabrication with timeconsuming packaging and integration processes. In this study, we developed a soft bio-integrated multifunctional device (SBMD) fabricated through the simple thermal evaporation and transfer processes. The intrinsically stretchable Au-SEBS film composed of thermally evaporated gold (Au) nanomembranes and an elastomeric substrate was applied to various functional modules that are capable of sensing the strain (up to $\sim 300 \%$ ), temperature (with a thermal sensitivity of $\sim 0.6 \Omega /{ }^{\circ} \mathrm{C}$ ), chemicals (at a concentration of $\mathrm{NaCl}$ of $\sim 0.5 \mathrm{wt} \%$ ), and even electrophysiological cardiac/muscle signals and showing thermal actuations $\left(80^{\circ} \mathrm{C}\right.$ at $\left.9 \mathrm{~V}\right)$. Specifically, such multifunctions of the SBMD were stably performed even on skin. Thus, we believe the SBMD would be a promising candidate for realizing soft bioelectronic systems.
\end{abstract}

Keywords: nanomembrane; crack-based sensor; stretchable electrode; wearable device; biomedical device

\section{Introduction}

Wearable devices used in smart healthcare applications can measure the electrophysiological signals from human skin to diagnose internal conditions and diseases [1-6]. Since the stable, long-term monitoring of biological signals is necessary to realize an accurate diagnosis, the electrical characteristics of sensors in wearable devices should not be lost, even if significantly deformed. Stretchable electrodes, for example, are not only used in wearable devices but are also epidermal and implantable sensors inserted into the body and actuators in soft robots; hence, they have gained increasing attention $[7,8]$. However, if the electrodes are detached from the skin owing to their mechanical modulus mismatch, the sensed signal cannot be read correctly because of an air gap caused by an inflow of air between the skin and electrodes. Therefore, many researchers have reported stretchable electrodes that can be attached conformally to the skin and accurately measure biological signals while having stable electrical characteristics for long-term use [9-12]. 
Conventional sensors manufactured on silicon substrates are rigid, brittle, and stiff, so it is difficult to attach them to the human body. Moreover, it is also difficult to obtain a stable signal during movements, because these sensors are not stretchable. Additionally, to achieve stable bio-signals despite these rigid properties, various methods such as buckled structure [13], noncoplanar [14], rigid islands [15], wavy interconnects, and complex geometry engineering [16-18] have been proposed. However, there is a problem with integration, because complex wavy interconnects occupy a larger area than the main sensor part. In addition, the fabrication of stretchable devices involves complicated multistep processes.

Therefore, researchers have proposed intrinsically stretchable materials for stretchable semiconductors [19-23] and organic electrodes [9,10,24-29]. Organic electrodes are soft, flexible, and soluble. Using these properties of polymers, they are made by mixing conductive fillers, such as metal nanowires and carbon materials with a flexible insulating polymer solution [24-29], or by polymerizing intrinsically conductive polymers from a monomer unit [30-32]. However, although these organic stretchable electrodes have excellent elasticity, they do not exhibit good electrical properties. In addition, they are vulnerable to various organic solvents used in semiconductor processes, which makes their integration difficult. Therefore, it is necessary to develop an intrinsically stretchable electrode that exhibits high electrical properties by using a relatively simple fabrication process.

For this demand, thermal evaporation has steadily studied for the preparation of stretchable conductors consisting of a gold nanomembrane on an elastomer surface (especially PDMS) [33-35]. It has been reported that thermally evaporated gold nanomembranes have three morphologies by the evaporation condition: microcracked, buckled, and smooth Among them, a microcracked gold nanomembrane-based elastomer conductor has advantages in its low electrical resistance, compatibility with the conventional semiconductor fabrication process, uniformity, simple one-step process and low fatigue for an extreme cyclic test, and so on [34]. Therefore, it was recently studied as a soft bioelectronics and neural interface [36-38]. However, there is no study using styrene-ethylene-butylene-styrene (SEBS) with a gold nanomembrane.

Here, we described a soft bio-integrated multifunctional device (SBMD) based on an intrinsically stretchable conducting nanomembrane supported on an elastomeric substrate. We fabricated a stretchable electrode by the direct deposition of a metal nanomembrane on the surface of a stretchable elastomer substrate using a thermal evaporator. The proposed electrodes showed that they are possible for fabricating patterned electrodes on one substrate with a simple one-step process. Moreover, the electrodes exhibited excellent stretchability ( $\sim 300 \%$ elongation) and low resistance. Finally, it was shown that it can be used sufficiently as a multifunctional wearable sensor that can detect deformation/electrochemical/temperature/electrophysiological signals from the skin and as a heater for thermotherapy (Figure 1a-c). 
(a)

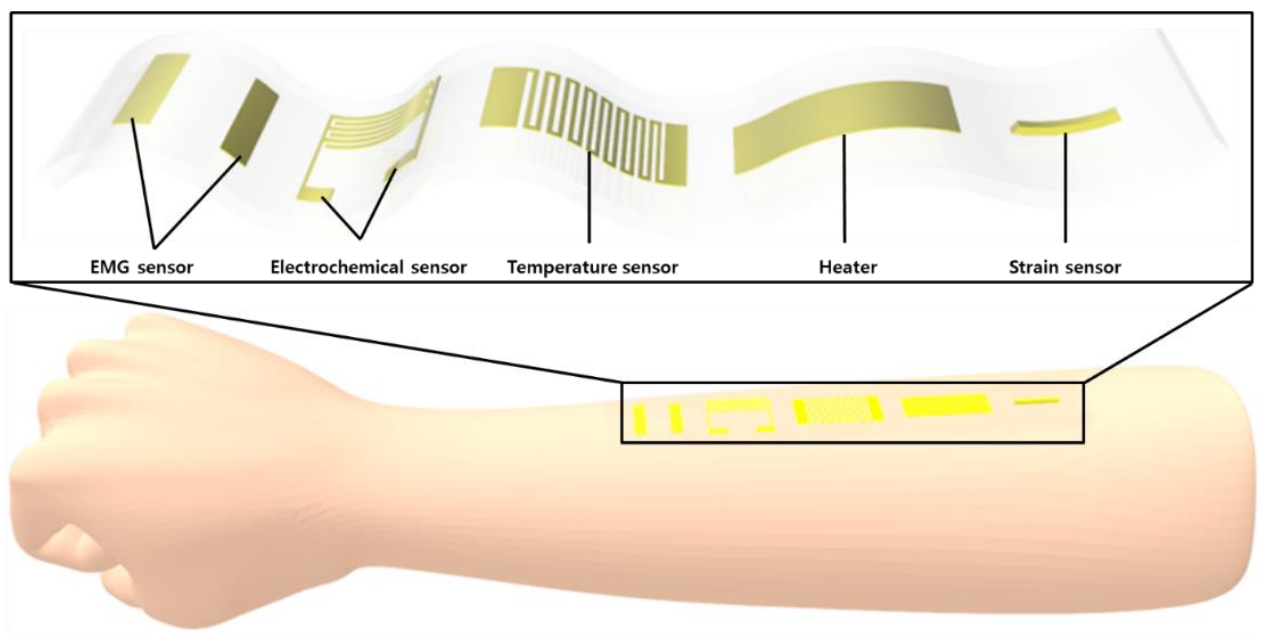

(b)

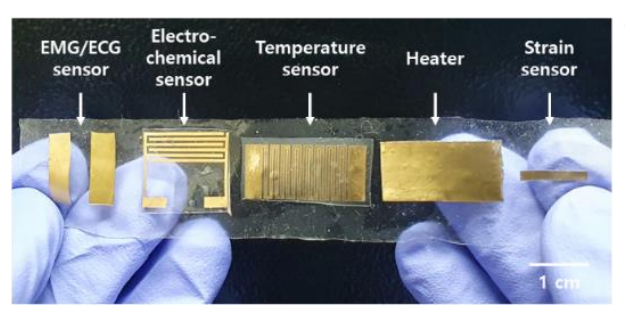

(c)

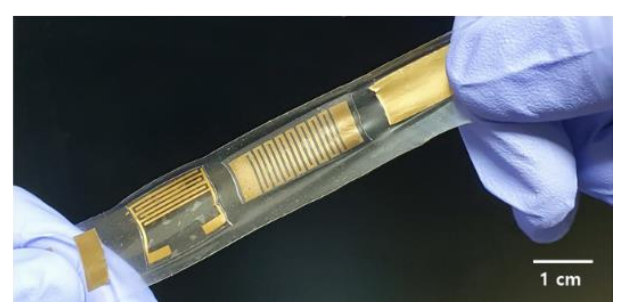

Figure 1. (a) Overall schematic of the soft bio-integrated multifunctional devices in intrinsically stretchable conducting nanomembrane electrodes. (b) Photograph of the device before being stretched. (c) Photograph of the device after being stretched.

\section{Materials and Methods}

\subsection{Preparation of the Au-SEBS Electrodes and Sensors}

All solvents were purchased from Sigma-Aldrich (Burlington, NJ, USA). The Au-SEBS electrodes were prepared according to a previous study [21]. First, $100 \mathrm{~mm} \times 100 \mathrm{~mm}$ glass plates (AMG glass, Uiwang, Korea) were prepared as substrates before gold deposition. The glass surfaces were cleaned for 2 min with oxygen plasma (100 W, 200 mTorr) using a reactive ion etcher machine (Oxford Plasmalab 80 Plus, Oxfordshire, UK) and sonicated in acetone, 2-propanol, and deionized (DI) water for $5 \mathrm{~min}$ each. After a gentle nitrogen gas blowing, the SEBS (Tuftec ${ }^{\mathrm{TM}} \mathrm{H} 1062$, Asahi Kasei Co., Tokyo, Japan) solution was drop-cast on top of a glass plate $(75 \mathrm{mg} / \mathrm{mL}$ in chloroform) and dried overnight. Next, gold nanomembranes with designated thicknesses $(10,30,50,70$, and $90 \mathrm{~nm})$ were directly deposited onto the surface of the SEBS films using the conventional thermal evaporation process ( 1.0 A per second). After peeling off the Au-SEBS films from the glass plate, they were cut to specific sizes for each purpose (strain sensor, heater, and electrophysiology). The wavy and interdigitated sensor devices were prepared using the same process, but a stainless-steel shadow mask (iNEX JK Co., Ltd., Hwaseong, Korea) was additionally used for the temperature sensor and electrochemical sensor. The patterned shadow mask (approximately $80 \mathrm{~mm} \times 80 \mathrm{~mm}$ ) was attached to the SEBS film on glass using commercial Kapton tape (KT-10, Bedell Co., Seoul, Korea) to create a sensor pattern. After the thermal evaporation of gold, the tape was peeled off, and the mask was removed from the surface of the SEBS film.

\subsection{Mechanical and Electrical Characterizations of Au-SEBS Electrodes}

To measure the resistance of the Au-SEBS films under strain, cyclic stretching tests were conducted using a motorized X-translation stage and its corresponding software (Jaeil Optical Corp., Daegu, Korea). During stretching, a source meter (Keithley 2450 Digital Multimeter, Clackamas, OR, USA) was used to monitor the real-time changes in the resistance of the Au-SEBS films. For morphological characterization, an optical microscope 
(BX51M, Olympus, Tokyo, Japan) was used to analyze the Au-SEBS films in each state (pristine, 100\% stretched, and released). The nanometric morphologies (Supplementary Figure S1) were characterized by a scanning electron microscope (JEOL, Seoul, Korea).

\subsection{Various Sensors and Heater Demonstration of the Au-SEBS Electrodes}

To prepare the strain sensor, the Au-SEBS film was cut to a determined width (from 1 to $5 \mathrm{~mm}$ ) and length $(2 \mathrm{~cm})$. The two ends of the samples were fixed on a motor-based one-axis stretcher using double-sided tape. The annealed copper wire and Au-SEBS sensor were placed in contact with liquid metal (EGaIn, Burlington, Sigma-Aldrich). The Au-SEBS strain sensor was stretched at a rate of $0.05 \mathrm{~mm} / \mathrm{s}$ but at $1 \mathrm{~mm} / \mathrm{s}$ for the cyclic test.

For the electrochemical sensor, various concentrations of $\mathrm{NaCl}$ solutions with DI water $(0,0.1,0.2,0.3,0.4$, and $0.5 \%)$ were prepared. The interdigitated Au-SEBS electrode films were attached to a glass plate (Marienfeld, Lauda-Königshofen, Germany), and commercial wires were connected on each pad of the electrode using liquid metal. They were totally fixed by polyimide tape. Then, they were immersed in $\mathrm{NaCl}$ solution. The source meter was used to measure the current change between the two electrodes.

For the temperature sensor, wavy Au-SEBS electrode films were attached to the glass plates, and commercial wires were connected on each pad of the electrode using liquid metal. Then, they were put on the top of the commercial hot plate machine. Temperature conditions were controlled by the hot plate control panel from $30{ }^{\circ} \mathrm{C}$ to $100{ }^{\circ} \mathrm{C}$. The resistance change was measured by the source meter. We waited $5 \mathrm{~min}$ from the moment each temperature condition was reached for stabilization of the resistance of the sensor.

For the heater, a $1 \mathrm{~cm} \times 2.5 \mathrm{~cm}$ Au-SEBS film was prepared. The film was placed in contact with commercial wires using liquid metal. The current was supplied from a power supply machine (Agilent E3647A, San Jose, CA, USA). The temperature of the heater was measured using a thermal imaging camera (E75SC, FLIR Systems, Inc., Wilsonville, OR, USA) for real-time monitoring.

\subsection{Measurement of Electrocardiogram and Electromyogram Signal from Human Skin}

For electrophysiological signal monitoring, the electromyogram (EMG) and electrocardiogram (ECG) signals were recorded using a bio-signal amplifier (Bio Amp FE231, AD Instruments, Dunedin, New Zealand) and a data acquisition device (PowerLab 8/35, AD Instruments). Action potential signals were filtered as the International Society of Electrophysiology and Kinesiology (ISEK) standard (1500-Hz low-pass filter). The sensing (SE) and reference (RE) electrodes were prepared by cutting the Au-SEBS electrode, and a commercial gel electrode (3M $2660 \mathrm{Ag} / \mathrm{AgCl}$ gel electrode) was used as the ground electrode.

For measuring the EMG sensing, the SE and RE were attached to the flexor digitorum superficialis $[39,40]$ of the right forearm, whereas the reference gel electrode was attached to the opposite side of the forearm. The volunteer was required to perform two simple hand gestures - that is, grasping and releasing of the fingers for $30 \mathrm{~s}$ each.

For measuring the electrocardiogram (ECG) sensing, the cardiac signal was measured by ECG equipment using the three proposed electrodes based on the standard 12-lead measurement method. The positive and negative electrodes were attached to the left and right forearms, respectively, and the reference electrode was attached to the left ankle. The electrodes were positioned based on Einthoven's triangle positioning for representative ECG electrode placement on humans [41,42].

\section{Results and Discussion}

\subsection{Stretching Test and Morphological Characterization of the Au-SEBS Electrodes}

After preparing the Au-SEBS electrodes (Figure 2a), we prepared the SEBS films with variable $\mathrm{Au}$ thicknesses to investigate the effect of the Au nanomembrane thickness on the electrical conductivity (Figure 2b). Naturally, the sheet resistance of the Au-SEBS film decreased as the Au nanomembrane thickness increased. The electrode with an $\mathrm{Au}$ 
nanomembrane thickness of $30 \mathrm{~nm}$ was conductive, indicating that the gold particles were sufficiently deposited to form an electrical pathway on the surface of the SEBS film.

(a)
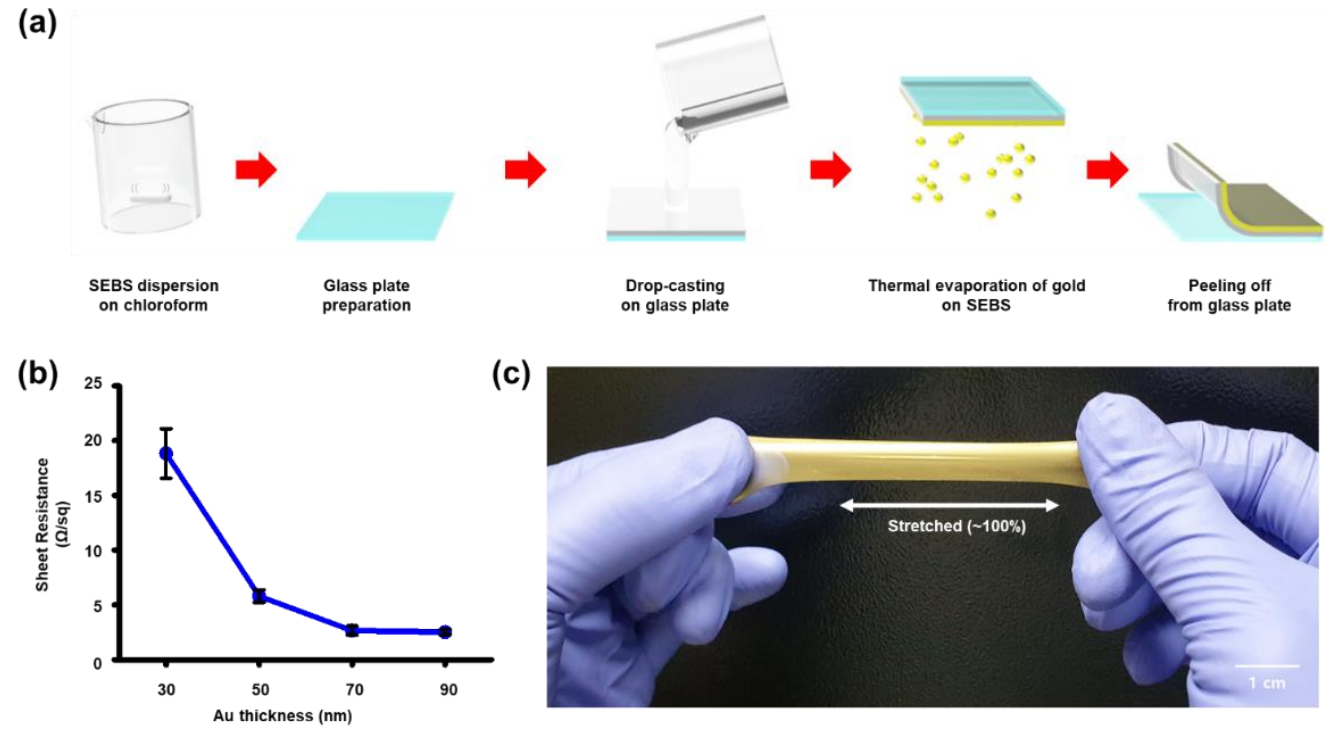

Figure 2. (a) Fabrication process of the Au-SEBS electrode. (b) Sheet resistance of the Au-SEBS electrodes varied by different Au thicknesses. (c) Photograph of the stretchable Au-SEBS electrode.

However, as seen from the optical microscope images in Figure 3, morphological changes were observed in the pristine, $100 \%$ stretched, and released states of the $\mathrm{Au}$ nanomembranes. Multiple micro-nanoscale cracks were seen on the surfaces of the electrodes. On stretching, the cracks spread widely, and larger gaps were observed between the Au particles. However, when they were released, the Au particles reconnected with each other, which indicates that the cracks in the Au nanostructure were supported by the elastic SEBS substrate (its elastic modulus was $~ 3.5 \mathrm{MPa}$ ); thus, stable electrical properties were retained during stretching and releasing.

(a)

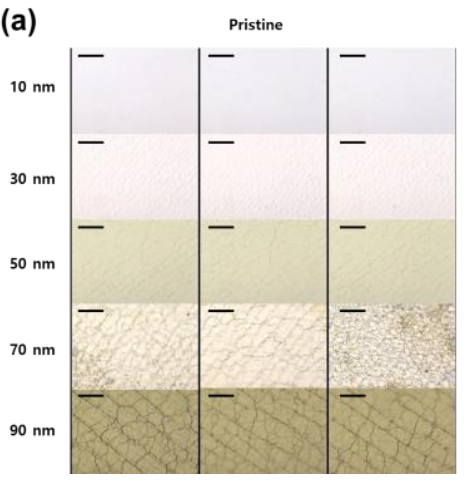

(b)

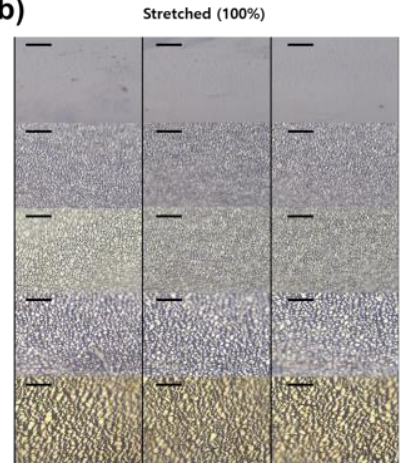

(c)

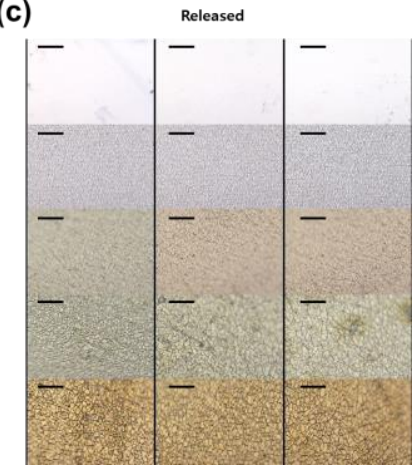

Figure 3. Optical images of the Au nanomembranes. (a) Pristine, (b) 100\% stretched by a motorized X-translation stage, and (c) released after stretching (scale bar: $20 \mu \mathrm{m}$ ).

\subsection{Strain Sensor}

We demonstrated the proposed electrode as a strain sensor. Achieving a high stretchable sensing range and high gauge factor in a strain sensor is challenging [43]. Although conventional strain sensors exhibit high gauge factor values for sensitivity, they have limited stretchable sensing ranges $[44,45]$. In contrast, while strain sensors exhibit relatively high stretchability ranging up to $70 \%$, they exhibit low sensitivity due to a low gauge factor [46,47]. Figure 4a shows the design rule for determining the Au thickness of the proposed strain sensor. As the maximum gauge factor increases, the Au thickness increases, 
and the electrical fracture strain decreases. To obtain a highly stretchable sensing range, we adopted a 30-nm-thick nanomembrane. For a higher gauge factor in a relatively narrow stretchable sensing range, a thicker nanomembrane can be considered. Figure $4 \mathrm{~b}$ shows the design rule for determining the width of the nanomembrane. If the gold nanomembrane becomes thicker, its initial resistance value would be lower than before. However, the initial resistance value was saturated for a width of $3 \mathrm{~mm}$, and no significant differences were observed even as the width increased. The gauge factor, compared to the same amount of strain, increased with a decrease in the initial resistance value. Therefore, we can conclude that the gauge factor value was the highest for the width of $3 \mathrm{~mm}$. Figure $4 \mathrm{c}$ shows the design rule for determining the stretchable sensing range of the strain sensor. Although a 3-mm-wide nanomembrane can be stretched up to $400 \%$, the linearity of the relative resistance decreases with an increase in the stretchable range. Linearity is a measure of the sensor performance. A low linearity indicates the need for sensor calibration, making the manufacturing process difficult [43]. Therefore, we adopted a 300\% stretchable sensing range with a high gauge factor and moderate linearity $(\sim 0.67)$. Figure $4 \mathrm{~d}$ shows the relative resistance-strain curves of the strain sensor. When the strain extended $300 \%$, the gauge factor value was approximately 134 , and an initial strain of $17 \%$ indicated residual strain. However, this value was negligible compared to the overall strain and resistance values. Figure $4 \mathrm{e}$ shows relative resistance-strain curve depicting the hysteresis of the selected strain sensor under a double sweep. There was not much difference in the relative resistance value within the loading-unloading cycle. Figure $4 \mathrm{f}$ shows the relative resistance-strain curve of the selected strain sensor from 100\% to 300\% during the loading-unloading cycle.

(a)

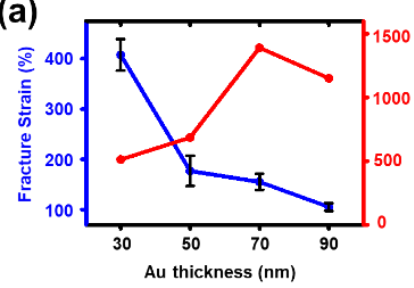

(d)

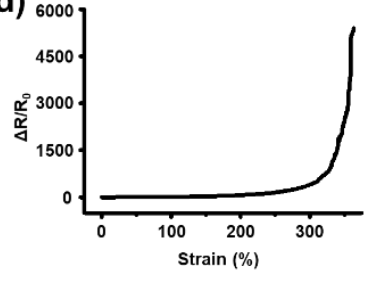

(b)

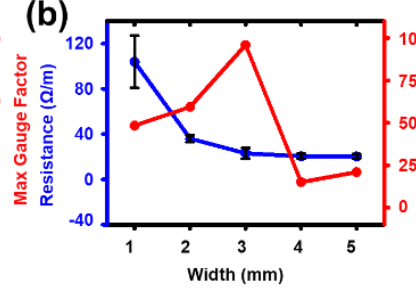

(e)

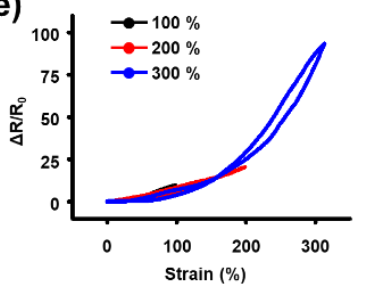

(c)

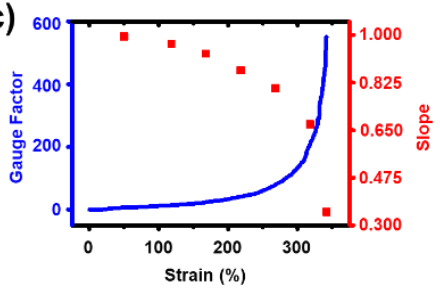

(f)

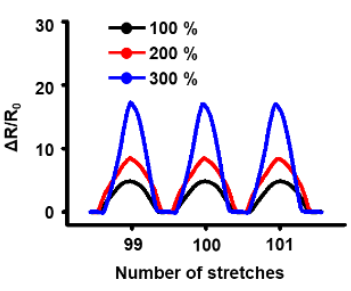

Figure 4. (a) Fracture strain and maximum gauge factor of the Au-SEBS strain sensor with their respective Au thicknesses. (b) Resistance trends and gauge factor as per the width of the strain sensor. (c) Gauge factor and linearity change as per the strain for determining the range of use of the sensor. (d) Relative resistance-strain curve depicting the sensitivity of the selected strain sensor. (e) Relative resistance-strain curve depicting the hysteresis of the selected strain sensor under a double sweep. (f) Reliable strain-sensing performance of the selected strain sensor under repeated stretching cycles.

\subsection{Electrochemical Sensor}

Interdigitated electrodes have been used as electrochemical biosensors for the past two decades and are often fabricated by complex steps. However, they do not require detection markers for specific analytes and a reference electrode, considering the interdigitated electrode sensor monitors changes in the current caused by the direct interaction between the sensor surface and the analytes [48-50]. Therefore, we prepared the Au-SEBS interdigitated electrode by attaching a patterned mask on the SEBS film before thermal evaporation. We selected sodium chloride $(\mathrm{NaCl})$ as our target analyte from numerous other bio-analytes in the body, considering they carry $0.5 \%$ of the total sweat [51,52]. Hence, we prepared mixtures of pure DI water with different concentrations of $\mathrm{NaCl}$ solutions 
for $\mathrm{NaCl}$ sensing. An interdigitated sensor is primitively categorized as a capacitive or impedimetric sensor [53-55], but using only simple setup at Figure 5a, we measured the concentration of $\mathrm{NaCl}$ in the solution by the interdigitated electrodes connected with a source meter. As the $\mathrm{NaCl}$ concentration increased, the mobile ions increased in the solution. We confirmed the current was increased as the $\mathrm{NaCl}$ concentration increased in the solution that the electrode was immersed in. Figure $5 \mathrm{~b}$ shows that sweat sensing is capable of diagnosing the health state of a subject even with other sensors attached.

(a)

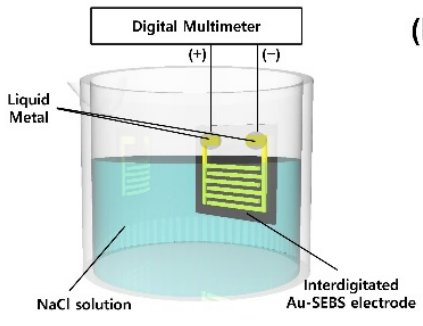

(d)

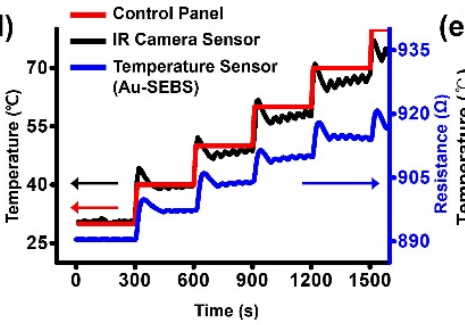

(b)

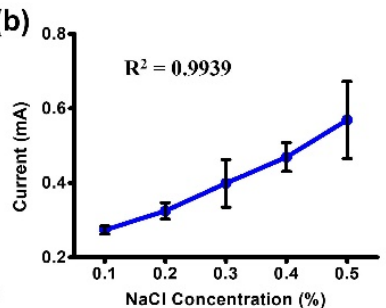

(e)

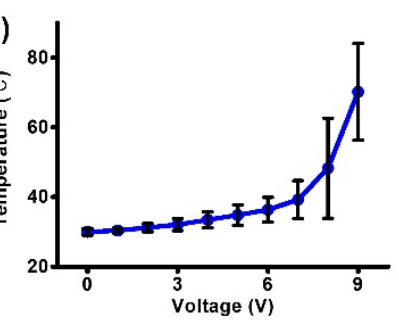

(c)

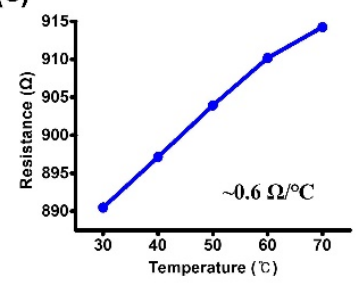

(f)

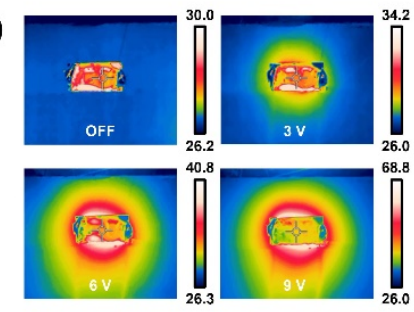

Figure 5. (a) Measurement setup of the Au-SEBS electrochemical sensor. (b) $\mathrm{NaCl}$ sensing of the electrochemical sensor. (c) Temperature-resistance correlation of Au-SEBS temperature sensor. (d) Real temperature differences between the control panel of a hot plate machine and IR camera sensor and the temperature sensing of the Au-SEBS temperature sensor in real time. (e) Heating performance of the heater following the voltage. (f) Thermal imaging of the Au-SEBS electrode heater in the off state, $3 \mathrm{~V}, 6 \mathrm{~V}$, and $9 \mathrm{~V}$ with scale bars.

\subsection{Temperature Sensor}

Temperature is an essential parameter, an important indicator for health monitoring of the human body. Various types of stretchable temperature sensors have been developed; two types are conductive composites (by thermal expansion differences) and resistive conductors on stretchable elastomer substrates (by resistance changes on conductors following the temperature) [56-59]. Conductive composites use various nanomaterials, including carbon nanotubes [60,61], graphene [62,63], conducting polymers $[64,65]$, and metal nanowires $[58,66,67]$. However, this type generally has a narrow temperature range, low accuracy, and slow response. [66] We used a wavy Au-SEBS electrode as a resistive temperature sensor. In Figure $5 c$, the Au-SEBS temperature sensor showed its temperature sensitivity $\left(\sim 0.6 \Omega /{ }^{\circ} \mathrm{C}\right)$. It was comparable with other nanomaterial-based temperature sensors $[56,66]$, specifically with copper or silver nanowires. Figure $5 d$ showed the correlation of the controlled temperature value we set on the hot plate machine and real-time temperature value fluctuation measured by an infrared thermal imaging camera. Basically, the heating stage we used could not keep constant temperature conditions, so real temperature conditions were continuously fluctuated. However, the Au-SEBS temperature sensor correctly followed the real temperature fluctuation trend measured by a thermal imaging camera, so it was shown that it can be worked as a reliable temperature sensor.

\subsection{Heater}

Among the basic elements used in skin wearable devices, heaters are most commonly used for thermotherapy. It is known that conventional heaters such as heat packs or wraps control their temperature by Joule heating, and the heating effect results in the thermal expansion of vascular systems and the surrounding tissues, which relieves pain [68]. 
Therefore, various kinds of stretchable heaters using metal nanowires [69-73], conducting polymers [74,75], and carbon materials [75-79] have been reported as wearable skin devices. In this study, we used the Au-SEBS electrode as a heater for application as a wearable healthcare device. Figure 5e,f showed the heating performance of the Au-SEBS electrode. Its temperature was raised at $77.6^{\circ} \mathrm{C}$ at $10 \mathrm{~V}$ at the maximum, but it was insufficient for other nanomaterial heaters like PEDOT:PSS (approximately $80^{\circ} \mathrm{C}$ at $7 \mathrm{~V}$ ) [75] or singlewalled carbon nanotube heaters (approximately $80^{\circ} \mathrm{C}$ at $5 \mathrm{~V}$ ) [78]. Nevertheless, the heater showed a sufficient heating temperature range $\left(30-80{ }^{\circ} \mathrm{C}\right.$ below $\left.10 \mathrm{~V}\right)$ as an epidermal heater device.

\subsection{Electrophysiology Measurement of the Human Body}

Biopotential monitoring from the human body (called "electrophysiology") provides direct evidence to determine a human body in a healthy state and diseased state. It can show a wide range of medical information about the patient [80-82]. Conventional electrodes used in electrophysiology are classified as wet and dry electrodes. As the gold standard, 3-M Ag/ AgCl gel electrode is an example of a wet-type electrode that is commonly used owing to low-impedance contact with the skin, reduced noise due to motion artifacts of a subject or wiring, and being easily disposable [83-85]. However, the performance is not long-lasting due to the constant gel dehydration with time, which sometimes results in skin irritation or allergic reactions, making them unsuitable for long-term bio-signal monitoring [85]. We used Au-SEBS films as bio-signal-sensing electrodes for measuring these EMG and ECG signals. Although our electrode was used as a dry electrode without a conductive gel, it was capable of effectively detecting the bio-signal when measuring the EMG and ECG in a simple experimental setup (Figure 6a) and determined the electrode positioning (Figure $6 \mathrm{~b}$ for EMG and Figure $6 \mathrm{~d}$ for ECG).

EMG show useful information about the skeletal muscles. Its activation was recorded by a form of electrical potentials produced by a contraction of specific muscles to which the electrode is attached. Motor unit action potential (MUAP) means a summation of the potentials evoked at several muscle fibers around the electrode [86]. From the neuromuscular junction, acetylcholine $(\mathrm{ACh})$ combines to $\mathrm{ACh}$ receptors on muscle tissue to start the action potential through depolarization by the inflow of sodium ions. EMG electrodes can detect the contraction and relaxation of the muscles in real time. It is an important tool for developing a human-machine interface and neuroprosthesis $[87,88]$. In Figure $6 c$, the surface EMG was measured by attaching the Au-SEBS electrode on the flexor digitorum superficialis $[39,40]$ of the right forearm (Figure 6c). The signals of two designated motions (grasping and releasing the one hand) were shown at each peak, but the difference of the two motion signals was not big, so it is suggested that the motion artifact was mixed in the EMG signals. The sensing signal scale (Y-axis scale) was not sufficient for other dry EMG electrodes using PEDOT:PSS [89] or silver electrodes [90]. However, for practical applications, it is still needed for external signal processing systems that are capable of the noise filtering.

An ECG can give us the electrical activity of the heart (a heart rhythm) in daily life. It is a simple but useful clinic tool to monitor and diagnose cardiovascular diseases such as arrhythmia, angina, and myocardial infarction from abnormal cardiac signals [91,92]. The ECG signal is analyzed by a distinct graph shape from the pulsing of the heart on the surface of the skin, mainly the left chest. Commonly, its distinct peaks are called P, Q, R, S, and T peaks [93]. In the heart, autorhythmic cells lead the heartbeat as the pacemaker. In the ECG signal, the $P$ peak is correlated on atrial depolarization of the cardiac cellular membrane by the inflow of sodium ions caused by the sinus node. Next, the QRS complex peaks mean the activation of the ventricles and widely spread electrical signals. Finally, the T peak occurs after the repolarization of the cardiac cellular membrane by the outflow of calcium and potassium ions. Depolarization is often maintained over two hundred milliseconds [94]. During the ECG measurements, we monitored five distinct peaks, revealing that cardiac activation of the volunteers clearly appeared in our electrode (Figure 6e). The sensing 
signal scale was comparable with the other dry ECG electrodes that were previously reported [95-97]. However, it showed only a basic characterization of the five peaks and needed to improve the performance for more precise cardiac diagnosis applications.

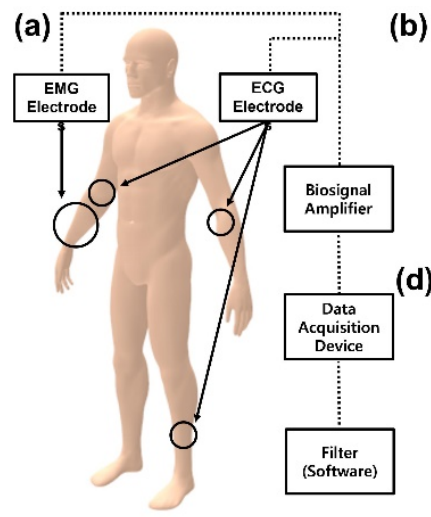

(b)

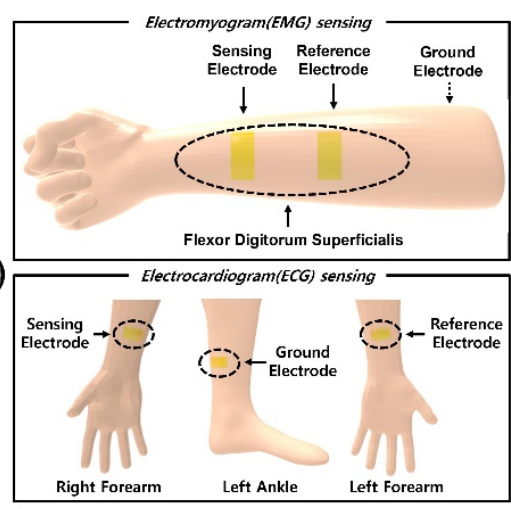

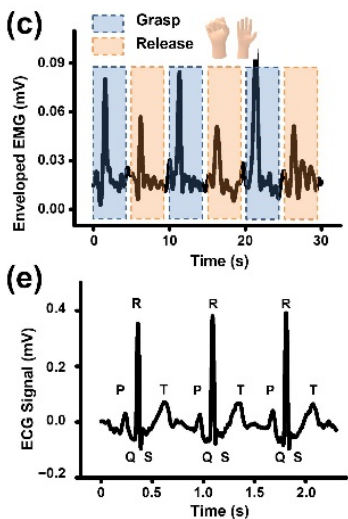

Figure 6. (a) Electrophysiology measurement setup. (b) Electrode positioning for EMG measurements. (c) EMG signals acquired from the forearm skin when the volunteer performed two hand gestures (grasping and releasing). (d) Electrode positioning for the ECG measurements. (e) ECG signals acquired from the volunteer's body. Several alphabetic captions expressed the cardiac signal state (PQRST peaks).

\section{Conclusions}

We fabricated soft bio-integrated multifunctional devices that can be attached to human skin to monitor and diagnose the health of a subject. Au-SEBS electrodes with varying thicknesses of the $\mathrm{Au}$ nanomembrane were prepared using the conventional evaporation process to investigate the effect of the thickness on the electrical properties of the sensor, such as the initial sheet resistance and electrical breakdown at the design stage. Furthermore, the morphological and mechanical analyses showed that the proposed sensors exhibited a stable low resistance under a strain based on the intrinsically stretchable conducting Au nanomembranes. After investigation, the selected Au-SEBS electrodes were used as strain sensors, electrochemical sensors, temperature sensors, heaters, and electrophysiological sensors (EMG and ECG).

The proposed Au-SEBS electrode-based sensors exhibited comparable performances to the previously reported wearable sensor devices and can be potential candidates for applications in wearable biomedical devices. If combined with signal processing systems, we expect that our Au-SEBS electrode can be widely applicable in the healthcare industry, such as when using the Internet of Things technology and deep neural networks in developing personal healthcare and diagnosis systems in the future.

Supplementary Materials: The following are available online at https: / www.mdpi.com/article / 10.3390/app11146562/s1: Figure S1: Scanning electron microscope images of Au-SEBS electrodes with designated thickness. Figure S2. (a) Simple working principal diagram of the proposed Au nanomembrane strain sensor. (b) Diagram of the Au nanomembrane strain sensor without a crack. (c) Diagram of the Au nanomembrane strain sensor elongated $\sim 100 \%$. (d) Diagram of the Au nanomembrane strain sensor elongated below the fracture strain. (e) Diagram of the Au nanomembrane strain sensor elongated above the fracture strain. Figure S3. Optical images of the Au nanomembrane of a 50-nm Au thickness when stretched 300\% at the motorized X-translation stage.

Author Contributions: S.L. designed and fabricated the stretchable polymer/Au nanomembrane sensor. K.K. performed the quantitative and qualitative experiments. Methodology, H.C. and J.Y.; validation, Y.K.; formal analysis, S.A.; investigation, H.J.; resources, D.S. (Donghee Son); data curation, K.P.; supervision, H.B. and D.S. (Donghee Son); and project administration, H.B. and D.S. (Duhwan Seong). All authors have read and agreed to the published version of the manuscript. 
Funding: This research was funded by the National Research Foundation of Korea (NRF) grant funded by the Korean government (MSIT) (No. 2020R1C1C1005567) and the Institute of Information \& Communications Technology Planning \& Evaluation (IITP) grant funded by the Korean government (MSIT) (No. S-2020-1443-000). This research was also supported by a ICT Creative Consilience program (IITP-2020-0-01821) supervised by the IITP (Institute for Information \& Communications Technology Planning \& Evaluation), a SMC-SKKU Future Convergence Research Program grant and a Korea Medical Device Development Fund grant funded by the Korean government (the Ministry of Science and ICT, the Ministry of Trade, Industry and Energy, the Ministry of Health \& Welfare, and the Ministry of Food and Drug Safety) (Project No: 202012D28).

Institutional Review Board Statement: Not applicable.

Informed Consent Statement: Not applicable.

Data Availability Statement: The data presented in this study is available in this article.

Conflicts of Interest: The authors declare no conflict of interest. The funders played no role in the design of this study; in the collection, analyses, and interpretation of the data, in the writing of the manuscript; or the decision to publish the results.

\section{References}

1. Amjadi, M.; Kyung, K.U.; Park, I.; Sitti, M. Stretchable, Skin-Mountable, and Wearable Strain Sensors and Their Potential Applications: A Review. Adv. Funct. Mater. 2016, 26, 1678-1698. [CrossRef]

2. Yeo, J.C.; Lim, C.T. Emerging flexible and wearable physical sensing platforms for healthcare and biomedical applications. Microsyst. Nanoeng. 2016, 2, 1-19. [CrossRef]

3. Lou, Z.; Wang, L.; Jiang, K.; Wei, Z.; Shen, G. Reviews of wearable healthcare systems: Materials, devices and system integration. Mater. Sci. Eng. R Reports 2020, 140, 100523. [CrossRef]

4. Koydemir, H.C.; Ozcan, A. Wearable and Implantable Sensors for Biomedical Applications. Annu. Rev. Anal. Chem. 2018, 11, 127-146. [CrossRef]

5. Ha, M.; Lim, S.; Ko, H. Wearable and flexible sensors for user-interactive health-monitoring devices. J. Mater. Chem. B 2018, 6, 4043-4064. [CrossRef] [PubMed]

6. Xiang, L.; Zeng, X.; Xia, F.; Jin, W.; Liu, Y.; Hu, Y. Recent Advances in Flexible and Stretchable Sensing Systems: From the Perspective of System Integration. ACS Nano 2020, 14, 6449-6469. [CrossRef]

7. Huang, S.; Liu, Y.; Zhao, Y.; Ren, Z.; Guo, C.F. Flexible Electronics: Stretchable Electrodes and Their Future. Adv. Funct. Mater. 2019, 29, 1805924. [CrossRef]

8. Wang, Y.; Li, X.; Hou, Y.; Yin, C.; Yin, Z. A review on structures, materials and applications of stretchable electrodes. Front. Mater. Sci. 2021, 15, 54-78. [CrossRef]

9. Park, M.; Park, J.; Jeong, U. Design of conductive composite elastomers for stretchable electronics. Nano Today 2014, 9, 244-260. [CrossRef]

10. Yao, S.; Zhu, Y. Nanomaterial-enabled stretchable conductors: Strategies, materials and devices. Adv. Mater. 2015, $27,1480-1511$. [CrossRef] [PubMed]

11. Trung, T.Q.; Lee, N.E. Recent Progress on Stretchable Electronic Devices with Intrinsically Stretchable Components. Adv. Mater. 2017, 29. [CrossRef]

12. Kim, Y.; Kweon, O.Y.; Won, Y.; Oh, J.H. Deformable and Stretchable Electrodes for Soft Electronic Devices. Macromol. Res. 2019, 27, 625-639. [CrossRef]

13. Sun, Y.; Choi, W.M.; Jiang, H.; Huang, Y.Y.; Rogers, J.A. Controlled buckling of semiconductor nanoribbons for stretchable electronics. Nat. Nanotechnol. 2006, 1, 201-207. [CrossRef] [PubMed]

14. Kim, D.H.; Song, J.; Won, M.C.; Kim, H.S.; Kim, R.H.; Liu, Z.; Huang, Y.Y.; Hwang, K.C.; Zhang, Y.W.; Rogers, J.A. Materials and noncoplanar mesh designs for integrated circuits with linear elastic responses to extreme mechanical deformations. Proc. Natl. Acad. Sci. USA 2008, 105, 18675-18680. [CrossRef] [PubMed]

15. Kim, D.H.; Xiao, J.; Song, J.; Huang, Y.; Rogers, J.A. Stretchable, curvilinear electronics based on inorganic materials. Adv. Mater. 2010, 22, 2108-2124. [CrossRef]

16. Kim, D.-H.; Lu, N.; Ma, R.; Kim, Y.-S.; Kim, R.-H.; Wang, S.; Wu, J.; Won, S.M.; Tao, H.; Islam, A.; et al. Epidermal Electronics. Science 2011, 333, 838-843. [CrossRef]

17. Son, D.; Lee, J.; Qiao, S.; Ghaffari, R.; Kim, J.; Lee, J.E.; Song, C.; Kim, S.J.; Lee, D.J.; Jun, S.W.; et al. Multifunctional wearable devices for diagnosis and therapy of movement disorders. Nat. Nanotechnol. 2014, 9, 397-404. [CrossRef]

18. Fan, J.A.; Yeo, W.H.; Su, Y.; Hattori, Y.; Lee, W.; Jung, S.Y.; Zhang, Y.; Liu, Z.; Cheng, H.; Falgout, L.; et al. Fractal design concepts for stretchable electronics. Nat. Commun. 2014, 5, 1-8. [CrossRef]

19. Oh, J.Y.; Rondeau-Gagné, S.; Chiu, Y.C.; Chortos, A.; Lissel, F.; Wang, G.J.N.; Schroeder, B.C.; Kurosawa, T.; Lopez, J.; Katsumata, T.; et al. Intrinsically stretchable and healable semiconducting polymer for organic transistors. Nature 2016, 539, 411-415. [CrossRef] 
20. Xu, J.; Wang, S.; Wang, G.J.N.; Zhu, C.; Luo, S.; Jin, L.; Gu, X.; Chen, S.; Feig, V.R.; To, J.W.F.; et al. Highly stretchable polymer semiconductor films through the nanoconfinement effect. Science 2017, 355, 59-64. [CrossRef]

21. Oh, J.Y.; Son, D.; Katsumata, T.; Lee, Y.; Kim, Y.; Lopez, J.; Wu, H.C.; Kang, J.; Park, J.; Gu, X.; et al. Stretchable self-healable semiconducting polymer film for active-matrix strain-sensing array. Sci. Adv. 2019, 5. [CrossRef]

22. Sim, K.; Rao, Z.; Kim, H.J.; Thukral, A.; Shim, H.; Yu, C. Fully rubbery integrated electronics from high effective mobility intrinsically stretchable semiconductors. Sci. Adv. 2019, 5, eaav5749. [CrossRef]

23. Tien, H.C.; Huang, Y.W.; Chiu, Y.C.; Cheng, Y.H.; Chueh, C.C.; Lee, W.Y. Intrinsically stretchable polymer semiconductors: Molecular design, processing and device applications. J. Mater. Chem. C 2021, 9, 2660-2684. [CrossRef]

24. Matsuhisa, N.; Inoue, D.; Zalar, P.; Jin, H.; Matsuba, Y.; Itoh, A.; Yokota, T.; Hashizume, D.; Someya, T. Printable elastic conductors by in situ formation of silver nanoparticles from silver flakes. Nat. Mater. 2017, 16, 834-840. [CrossRef]

25. Wang, Y.; Zhu, C.; Pfattner, R.; Yan, H.; Jin, L.; Chen, S.; Molina-Lopez, F.; Lissel, F.; Liu, J.; Rabiah, N.I.; et al. A highly stretchable, transparent, and conductive polymer. Sci. Adv. 2017, 3, e1602076. [CrossRef]

26. Kim, S.H.; Seo, H.; Kang, J.; Hong, J.; Seong, D.; Kim, H.J.; Kim, J.; Mun, J.; Youn, I.; Kim, J.; et al. An Ultrastretchable and SelfHealable Nanocomposite Conductor Enabled by Autonomously Percolative Electrical Pathways. ACS Nano 2019, 13, 6531-6539. [CrossRef]

27. Lynch, P.J.; Ogilvie, S.P.; Large, M.J.; Graf, A.A.; O’Mara, M.A.; Taylor, J.; Salvage, J.P.; Dalton, A.B. Graphene-based printable conductors for cyclable strain sensors on elastomeric substrates. Carbon 2020, 169, 25-31. [CrossRef]

28. Seyedin, S.; Uzun, S.; Levitt, A.; Anasori, B.; Dion, G.; Gogotsi, Y.; Razal, J.M. MXene Composite and Coaxial Fibers with High Stretchability and Conductivity for Wearable Strain Sensing Textiles. Adv. Funct. Mater. 2020, 30. [CrossRef]

29. Garcia, J.R.; O'Suilleabhain, D.; Kaur, H.; Coleman, J.N. A Simple Model Relating Gauge Factor to Filler Loading in Nanocomposite Strain Sensors. ACS Appl. Nano Mater. 2021, 4, 2876-2886. [CrossRef]

30. Jaymand, M. Recent progress in chemical modification of polyaniline. Prog. Polym. Sci. 2013, 38, 1287-1306. [CrossRef]

31. Gueye, M.N.; Carella, A.; Faure-Vincent, J.; Demadrille, R.; Simonato, J.P. Progress in understanding structure and transport properties of PEDOT-based materials: A critical review. Prog. Mater. Sci. 2020, 108, 100616. [CrossRef]

32. Pang, A.L.; Arsad, A.; Ahmadipour, M. Synthesis and factor affecting on the conductivity of polypyrrole: A short review. Polym. Adv. Technol. 2021, 32, 1428-1454. [CrossRef]

33. Lacour, S.P.; Chan, D.; Wagner, S.; Li, T.; Suo, Z. Mechanisms of reversible stretchability of thin metal films on elastomeric substrates. Appl. Phys. Lett. 2006, 88, 204103. [CrossRef]

34. Graudejus, O.; Görrn, P.; Wagner, S. Controlling the morphology of gold films on poly(dimethylsiloxane). ACS Appl. Mater. Interfaces 2010, 2, 1927-1933. [CrossRef]

35. Koshi, T.; Iwase, E. Crack-configuration analysis of metal conductive track embedded in stretchable elastomer. Micromachines 2018, 9, 130. [CrossRef]

36. Liu, Z.; Wang, X.; Qi, D.; Xu, C.; Yu, J.; Liu, Y.; Jiang, Y.; Liedberg, B.; Chen, X. High-Adhesion Stretchable Electrodes Based on Nanopile Interlocking. Adv. Mater. 2017, 29, 1603382. [CrossRef] [PubMed]

37. Yan, X.; Liu, Z.; Zhang, Q.; Lopez, J.; Wang, H.; Wu, H.C.; Niu, S.; Yan, H.; Wang, S.; Lei, T.; et al. Quadruple H-Bonding cross-linked supramolecular polymeric materials as substrates for stretchable, antitearing, and self-healable thin film electrodes. $J$. Am. Chem. Soc. 2018, 140, 5280-5289. [CrossRef]

38. Song, K., II; Seo, H.; Seong, D.; Kim, S.; Yu, K.J.; Kim, Y.C.; Kim, J.; Kwon, S.J.; Han, H.S.; Youn, I.; et al. Adaptive self-healing electronic epineurium for chronic bidirectional neural interfaces. Nat. Commun. 2020, 11. [CrossRef]

39. Reddy, N.P.; Gupta, V. Toward direct biocontrol using surface EMG signals: Control of finger and wrist joint models. Med. Eng. Phys. 2007, 29, 398-403. [CrossRef]

40. Mohideen, A.J.H.; Sidek, S.N. Development of EMG circuit to study the relationship between flexor digitorum superficialis muscle activity and hand grip strength. In Proceedings of the 2011 4th International Conference on Mechatronics (ICOM), Kuala Lumpur, Malaysia, 17-19 May 2011; pp. 17-19. [CrossRef]

41. Gargiulo, G.D.; Bifulco, P.; Cesarelli, M.; McEwan, A.L.; Moeinzadeh, H.; O’loughlin, A.; Shugman, I.M.; Tapson, J.C.; Thiagalingam, A. On the einthoven triangle: A critical analysis of the single rotating dipole hypothesis. Sensors 2018, 18, 2353. [CrossRef]

42. Kolanowska, A.; Herman, A.P.; Jędrysiak, R.G.; Boncel, S. Carbon nanotube materials for electrocardiography. RSC Adv. 2021, 11, 3020-3042. [CrossRef]

43. Song, Z.; Li, W.; Bao, Y.; Han, F.; Gao, L.; Xu, J.; Ma, Y.; Han, D.; Niu, L. Breathable and Skin-Mountable Strain Sensor with Tunable Stretchability, Sensitivity, and Linearity via Surface Strain Delocalization for Versatile Skin Activities' Recognition. ACS Appl. Mater. Interfaces 2018, 10, 42826-42836. [CrossRef]

44. Kang, D.; Pikhitsa, P.V.; Choi, Y.W.; Lee, C.; Shin, S.S.; Piao, L.; Park, B.; Suh, K.Y.; Kim, T.I.; Choi, M. Ultrasensitive mechanical crack-based sensor inspired by the spider sensory system. Nature 2014, 516, 222-226. [CrossRef] [PubMed]

45. Yang, T.; Li, X.; Jiang, X.; Lin, S.; Lao, J.; Shi, J.; Zhen, Z.; Li, Z.; Zhu, H. Structural engineering of gold thin films with channel cracks for ultrasensitive strain sensing. Mater. Horiz. 2016, 3, 248-255. [CrossRef]

46. Kim, J.; Park, S.J.; Nguyen, T.; Chu, M.; Pegan, J.D.; Khine, M. Highly stretchable wrinkled gold thin film wires. Appl. Phys. Lett. 2016, 108. [CrossRef] 
47. Lee, P.; Lee, J.; Lee, H.; Yeo, J.; Hong, S.; Nam, K.H.; Lee, D.; Lee, S.S.; Ko, S.H. Highly stretchable and highly conductive metal electrode by very long metal nanowire percolation network. Adv. Mater. 2012, 24, 3326-3332. [CrossRef]

48. Liu, D.; Perdue, R.K.; Sun, L.; Crooks, R.M. Immobilization of DNA onto poly(dimethylsiloxane) surfaces and application to a microelectrochemical enzyme-amplified DNA hybridization assay. Langmuir 2004, 20, 5905-5910. [CrossRef]

49. Nebling, E.; Grunwald, T.; Albers, J.; Schäfer, P.; Hintsche, R. Electrical Detection of Viral DNA Using Ultramicroelectrode Arrays. Anal. Chem. 2004, 76, 689-696. [CrossRef] [PubMed]

50. Varshney, M.; Li, Y. Interdigitated array microelectrodes based impedance biosensors for detection of bacterial cells. Biosens. Bioelectron. 2009, 24, 2951-2960. [CrossRef] [PubMed]

51. Colin, S.; Krier, G.; Jolibois, H.; Hachimi, A.; Muller, J.F.; Chambaudet, A. Characterization of the corrosion layer of copper-nickel alloys in a synthetic sweat medium by FTMS and LAMMA laser microprobes. Appl. Surf. Sci. 1998, 125, 29-45. [CrossRef]

52. Ferreira, S.C.; Ariza, E.; Rocha, L.A.; Gomes, J.R.; Carvalho, P.; Vaz, F.; Fernandes, A.C.; Rebouta, L.; Cunha, L.; Alves, E.; et al. Tribocorrosion behaviour of ZrOxNy thin films for decorative applications. Surf. Coatings Technol. 2006, 200, 6634-6639. [CrossRef]

53. Kandala, C.V.K.; Butts, C.L. Design and performance of a capacitor sensor and impedance analyzer for nondestructive moisture content determination. Sens. Instrum. Food Qual. Saf. 2008, 2, 240-246. [CrossRef]

54. Blume, S.O.P.; Ben-Mrad, R.; Sullivan, P.E. Modelling the capacitance of multi-layer conductor-facing interdigitated electrode structures. Sens. Actuators B Chem. 2015, 213, 423-433. [CrossRef]

55. Sathya, S.; Muruganand, S.; Manikandan, N.; Karuppasamy, K. Design of capacitance based on interdigitated electrode for BioMEMS sensor application. Mater. Sci. Semicond. Process. 2019, 101, 206-213. [CrossRef]

56. Li, Q.; Zhang, L.N.; Tao, X.M.; Ding, X. Review of Flexible Temperature Sensing Networks for Wearable Physiological Monitoring. Adv. Healthc. Mater. 2017, 6, 1601371. [CrossRef] [PubMed]

57. Liu, Y.; Pharr, M.; Salvatore, G.A. Lab-on-Skin: A Review of Flexible and Stretchable Electronics for Wearable Health Monitoring. ACS Nano 2017, 11, 9614-9635. [CrossRef] [PubMed]

58. Cui, Z.; Poblete, F.R.; Zhu, Y. Tailoring the Temperature Coefficient of Resistance of Silver Nanowire Nanocomposites and their Application as Stretchable Temperature Sensors. ACS Appl. Mater. Interfaces 2019, 11, 17836-17842. [CrossRef] [PubMed]

59. Yang, Y.; Deng, Z.D. Stretchable sensors for environmental monitoring. Appl. Phys. Rev. 2019, 6. [CrossRef]

60. Amjadi, M.; Yoon, Y.J.; Park, I. Ultra-stretchable and skin-mountable strain sensors using carbon nanotubes-Ecoflex nanocomposites. Nanotechnology 2015, 26. [CrossRef]

61. Zhang, C.; Zhang, Q.; Zhang, D.; Wang, M.; Bo, Y.; Fan, X.; Li, F.; Liang, J.; Huang, Y.; Ma, R.; et al. Highly Stretchable Carbon Nanotubes/Polymer Thermoelectric Fibers. Nano Lett. 2021, 21, 1047-1055. [CrossRef]

62. Wang, Z.; Gao, W.; Zhang, Q.; Zheng, K.; Xu, J.; Xu, W.; Shang, E.; Jiang, J.; Zhang, J.; Liu, Y. 3D-Printed Graphene/Polydimethylsiloxane Composites for Stretchable and Strain-Insensitive Temperature Sensors. ACS Appl. Mater. Interfaces 2019, 11, 1344-1352. [CrossRef]

63. Zhang, F.; Hu, H.; Islam, M.; Peng, S.; Wu, S.; Lim, S.; Zhou, Y.; Wang, C.H. Multi-modal strain and temperature sensor by hybridizing reduced graphene oxide and PEDOT:PSS. Compos. Sci. Technol. 2020, 187, 107959. [CrossRef]

64. Hong, S.Y.; Lee, Y.H.; Park, H.; Jin, S.W.; Jeong, Y.R.; Yun, J.; You, I.; Zi, G.; Ha, J.S. Stretchable Active Matrix Temperature Sensor Array of Polyaniline Nanofibers for Electronic Skin. Adv. Mater. 2016, 28, 930-935. [CrossRef]

65. Li, F.; Liu, Y.; Shi, X.; Li, H.; Wang, C.; Zhang, Q.; Ma, R.; Liang, J. Printable and Stretchable Temperature-Strain Dual-Sensing Nanocomposite with High Sensitivity and Perfect Stimulus Discriminability. Nano Lett. 2020, 20, 6176-6184. [CrossRef]

66. Youn, D.Y.; Jung, U.; Naqi, M.; Choi, S.J.; Lee, M.G.; Lee, S.; Park, H.J.; Kim, I.D.; Kim, S. Wireless Real-Time Temperature Monitoring of Blood Packages: Silver Nanowire-Embedded Flexible Temperature Sensors. ACS Appl. Mater. Interfaces 2018, 10, 44678-44685. [CrossRef]

67. Han, S.; Kim, M.K.; Wang, B.; Wie, D.S.; Wang, S.; Lee, C.H. Mechanically Reinforced Skin-Electronics with Networked Nanocomposite Elastomer. Adv. Mater. 2016, 28, 10257-10265. [CrossRef]

68. Brosseau, L.; Yonge, K.; Robinson, V.; Marchand, S.; Judd, M.; Wells, G.; Tugwell, P. Thermotherapy for treatment of osteo-arthritis. Physiotherapy 2003, 89, 694-695. [CrossRef]

69. Choi, S.; Park, J.; Hyun, W.; Kim, J.; Kim, J.; Lee, Y.B.; Song, C.; Hwang, H.J.; Kim, J.H.; Hyeon, T.; et al. Stretchable Heater Using Ligand-Exchanged Silver Nanowire Nanocomposite for Wearable Articular Thermotherapy. ACS Nano 2015, 9, 6626-6633. [CrossRef]

70. An, B.W.; Gwak, E.J.; Kim, K.; Kim, Y.C.; Jang, J.; Kim, J.Y.; Park, J.U. Stretchable, Transparent Electrodes as Wearable Heaters Using Nanotrough Networks of Metallic Glasses with Superior Mechanical Properties and Thermal Stability. Nano Lett. 2016, 16, 471-478. [CrossRef]

71. Huang, Q.; Al-Milaji, K.N.; Zhao, H. Inkjet Printing of Silver Nanowires for Stretchable Heaters. ACS Appl. Nano Mater. 2018, 1, 4528-4536. [CrossRef]

72. Wang, J.; Zhang, K.; Wang, J.; Zhang, M.; Zhou, Y.; Cheng, J.; Kong, D. Strain-invariant conductance in an elastomeric nanocomposite mesh conductor for stretchable electronics. J. Mater. Chem. C 2020, 8, 9440-9448. [CrossRef]

73. Guo, Z.; Sun, C.; Zhao, J.; Cai, Z.; Ge, F. Low-Voltage Electrical Heater Based on One-Step Fabrication of Conductive Cu Nanowire Networks for Application in Wearable Devices. Adv. Mater. Interfaces 2021, 8, 2001695. [CrossRef]

74. Zhou, J.; Mulle, M.; Zhang, Y.; Xu, X.; Li, E.Q.; Han, F.; Thoroddsen, S.T.; Lubineau, G. High-ampacity conductive polymer microfibers as fast response wearable heaters and electromechanical actuators. J. Mater. Chem. C 2016, 4, 1238-1249. [CrossRef] 
75. Zhou, R.; Li, P.; Fan, Z.; Du, D.; Ouyang, J. Stretchable heaters with composites of an intrinsically conductive polymer, reduced graphene oxide and an elastomer for wearable thermotherapy. J. Mater. Chem. C 2017, 5, 1544-1551. [CrossRef]

76. Yoon, Y.H.; Song, J.W.; Kim, D.; Kim, J.; Park, J.K.; Oh, S.K.; Han, C.S. Transparent film heater using single-walled carbon nanotubes. Adv. Mater. 2007, 19, 4284-4287. [CrossRef]

77. Li, Y.Q.; Zhu, W.B.; Yu, X.G.; Huang, P.; Fu, S.Y.; Hu, N.; Liao, K. Multifunctional Wearable Device Based on Flexible and Conductive Carbon Sponge/Polydimethylsiloxane Composite. ACS Appl. Mater. Interfaces 2016, 8, 33189-33196. [CrossRef]

78. Kim, Y.; Lee, H.R.; Saito, T.; Nishi, Y. Ultra-thin and high-response transparent and flexible heater based on carbon nanotube film. Appl. Phys. Lett. 2017, 110, 153301. [CrossRef]

79. Sun, W.J.; Xu, L.; Jia, L.C.; Zhou, C.G.; Xiang, Y.; Yin, R.H.; Yan, D.X.; Tang, J.H.; Li, Z.M. Highly conductive and stretchable carbon nanotube/thermoplastic polyurethane composite for wearable heater. Compos. Sci. Technol. 2019, 181, 107695. [CrossRef]

80. Choi, S.; Lee, H.; Ghaffari, R.; Hyeon, T.; Kim, D.H. Recent Advances in Flexible and Stretchable Bio-Electronic Devices Integrated with Nanomaterials. Adv. Mater. 2016, 28, 4203-4218. [CrossRef]

81. Zheng, K.; Chen, S.; Zhu, L.; Zhao, J.; Guo, X. Large Area Solution Processed Poly (Dimethylsiloxane)-Based Thin Film Sensor Patch for Wearable Electrocardiogram Detection. IEEE Electron Device Lett. 2018, 39, 424-427. [CrossRef]

82. Kisannagar, R.R.; Jha, P.; Navalkar, A.; Maji, S.K.; Gupta, D. Fabrication of Silver Nanowire/Polydimethylsiloxane Dry Electrodes by a Vacuum Filtration Method for Electrophysiological Signal Monitoring. ACS Omega 2020, 5, 10260-10265. [CrossRef]

83. Peng, H.L.; Liu, J.Q.; Dong, Y.Z.; Yang, B.; Chen, X.; Yang, C.S. Parylene-based flexible dry electrode for bioptential recording. Sens. Actuators B Chem. 2016, 231, 1-11. [CrossRef]

84. Portelli, A.J.; Nasuto, S.J. Design and development of non-contact bio-potential electrodes for pervasive health monitoring applications. Biosensors 2017, 7, 2. [CrossRef] [PubMed]

85. Zahed, M.A.; Das, P.S.; Maharjan, P.; Barman, S.C.; Sharifuzzaman, M.; Yoon, S.H.; Park, J. yeong Flexible and robust dry electrodes based on electroconductive polymer spray-coated 3D porous graphene for long-term electrocardiogram signal monitoring system. Carbon 2020, 165, 26-36. [CrossRef]

86. Barbado, D.; Elvira, J.L.L. Medicina del Deporte. Rev. Andaluza Med. Deport. 2015, 8, 79-85.

87. Zeng, X.; Dong, Y.; Wang, X. Flexible electrode by hydrographic printing for surface electromyography monitoring. Materials 2020, 13, 2339. [CrossRef]

88. Roland, T.; Wimberger, K.; Amsuess, S.; Russold, M.F.; Baumgartner, W. An Insulated Flexible Sensor for Stable Electromyography Detection: Application to Prosthesis Control. Sensors 2019, 19, 961. [CrossRef]

89. Wang, K.; Parekh, U.; Pailla, T.; Garudadri, H.; Gilja, V.; Ng, T.N. Stretchable Dry Electrodes with Concentric Ring Geometry for Enhancing Spatial Resolution in Electrophysiology. Adv. Healthc. Mater. 2017, 6, 1700552. [CrossRef]

90. Hu, Y.; Wang, H.; Sheikhnejad, O.; Xiong, Y.; Gu, H.; Zhu, P.; Li, G.; Sun, R.; Wong, C.P. Stretchable and printable medical dry electrode arrays on textile for electrophysiological monitoring. In Proceedings of the 2019 IEEE 69th Electronic Components and Technology Conference (ECTC), Las Vegas, NV, USA, 28-31 May 2019; pp. 243-248. [CrossRef]

91. Koo, J.H.; Jeong, S.; Shim, H.J.; Son, D.; Kim, J.; Kim, D.C.; Choi, S.; Hong, J.I.; Kim, D.H. Wearable Electrocardiogram Monitor Using Carbon Nanotube Electronics and Color-Tunable Organic Light-Emitting Diodes. ACS Nano 2017, 11, 10032-10041. [CrossRef]

92. Liu, B.; Tang, H.; Luo, Z.; Zhang, W.; Tu, Q.; Jin, X. Wearable carbon nanotubes-based polymer electrodes for ambulatory electrocardiographic measurements. Sens. Actuators A Phys. 2017, 265, 79-85. [CrossRef]

93. Pani, D.; Achilli, A.; Bonfiglio, A. Survey on Textile Electrode Technologies for Electrocardiographic (ECG) Monitoring, from Metal Wires to Polymers. Adv. Mater. Technol. 2018, 3, 1800008. [CrossRef]

94. Näbauer, M.; Callewaert, G.; Cleemann, L.; Morad, M. Regulation of calcium release is gated by calcium current, not gating charge, in cardiac myocytes. Science 1989, 244, 800-803. [CrossRef] [PubMed]

95. Myers, A.C.; Huang, H.; Zhu, Y. Wearable silver nanowire dry electrodes for electrophysiological sensing. RSC Adv. 2015, 5, 11627-11632. [CrossRef]

96. Hwang, S.W.; Lee, C.H.; Cheng, H.; Jeong, J.W.; Kang, S.K.; Kim, J.H.; Shin, J.; Yang, J.; Liu, Z.; Ameer, G.A.; et al. Biodegradable elastomers and silicon nanomembranes/nanoribbons for stretchable, transient electronics, and biosensors. Nano Lett. 2015, 15, 2801-2808. [CrossRef]

97. Zhou, W.; Yao, S.; Wang, H.; Du, Q.; Ma, Y.; Zhu, Y. Gas-Permeable, Ultrathin, Stretchable Epidermal Electronics with Porous Electrodes. ACS Nano 2020, 14, 5798-5805. [CrossRef] [PubMed] 